REVISÃO / REVIEW

\title{
EPIDEMIOLOGIA COMPARATIVA ENTRE OS PATOSSISTEMAS TEMPERADO E TROPICAL: CONSEQÜÊNCIAS PARA A RESISTÊNCIA A FUNGICIDAS
}

\author{
ARMANDO BERGAMIN FILHO \& LILIAN AMORIM \\ Departamento de Entomologia, Fitopatologia e Zoologia Agrícola, ESALQ-USP, CEP 13418-900, Piracicaba-SP, \\ e-mail: abergami@carpa.ciagri.usp.br
}

(Aceito para publicação em 20/04/2001)

Autor para correspondência: Armando Bergamin Filho

BERGAMIN FILHO, A. \& AMORIM, L. Epidemiologia comparativa entre os patossistemas temperado e tropical: conseqüências para a resistência a fungicidas. Fitopatologia Brasileira 26:119-127. 2001.

\section{RESUMO}

O patossistema tropical difere do patossistema temperado tanto em estrutura quanto em comportamento. Nesta revisão, ambos os patossistemas são caracterizados e, com base nessa caracterização, o risco de origem e de seleção de resistência a fungicidas é discutido para ambas as situações. As características diferenciais relevantes para análise foram: sobrevivência I (entre estações de cultivo); sobrevivência II (entre ciclos do patógeno); taxa aparente de infecção; via anti- horária de infecção; ingresso e/ou manutenção de mutantes resistentes; via horária de infecção; persistência de mutantes resistentes; adaptabilidade dos mutantes resistentes. Concluise que o patossistema tropical não apresenta risco maior para a seleção de mutantes resistentes, mas pode, em alguns casos, apresentar risco maior de origem de mutantes resistentes.

Palavras-chave: sobrevivência de patógenos, taxa de infecção, mutante resistente.

\section{ABSTRACT \\ Comparative epidemiology between temperate and tropical pathosystems: its consequences for fungicide resistance}

Tropical and temperate pathosystems differ in structure and behavior. In this article, both pathosystems are characterized and the risk of origin and selection of fungicide resistance is discussed for both situations. The differential characteristics found relevant were: survival I (between crop seasons); survival II (between cycles of the pathogen); apparent infection rate; ingress and/or survival of resistant mutants; clockwise manner of infection; persistence of resistant mutants; fitness of resistant mutants. It is concluded that the tropical pathosystem does not have a higher risk of selecting resistant mutants. However, in some cases, a higher number of resistant mutants can be originated in tropical pathosystems.

\section{O PATOSSISTEMA TEMPERADO}

"Uma doença infecciosa pode se manter unicamente por meio de contínuas reinfecções baseadas na cadeia de infecção. Por cadeia de infecção entende-se a transmissão contínua, seriada, de material infetivo de uma planta para outra" (Gäumann, 1950). Essa frase, síntese do principal princípio da epidemiologia temperada, contém informação reveladora: epidemias só ocorrem na natureza caso propágulos do patógeno (produzidos em determinada planta) sejam liberados, transportados e depositados em outra planta suscetível.

Os autores, cada um a sua maneira, chamam a atenção para esse princípio. Vanderplank (1963) é suficientemente claro quando diz: "o tipo de multiplicação de doença que nos interessa implica na movimentação do patógeno de uma lesão para outra, ou de uma planta para outra, caso o patógeno seja sistêmico. A multiplicação do patógeno dentro da lesão ou a multiplicação de um patógeno sistêmico dentro da planta não é relevante aqui". Morrall \& Verma (1981) transcrevem essa mesma frase e complementam: "o ponto fundamental é que o crescimento logístico aplica-se a populações de 'unidades de doença', tais como plantas infetadas ou lesões em plantas, e não ao tamanho dessas unidades". Outros autores também comungam desta opinião: Zadoks (1972) enfatiza que "na epidemiologia, o nivel de integração mais baixo é o ciclo de infecção recorrente, com suas várias fases, e o próximo nivel mais alto de integração pode ser a epidemia como um todo, consistindo de vários ciclos de infecção superpostos". Kranz (1978), por sua vez, menciona que "cada ciclo de infecção resulta em uma ou mais lesões filhas no próximo ciclo da doença". Não é de admirar, portanto, que a maior parte da recente pesquisa epidemiológica seja voltada para a tarefa de identificar e quantificar os diferentes fatores que condicionam a infecção 
e, conseqüentemente, o aparecimento de novas lesões (Campbell \& Madden, 1990).

\section{Um modelo para o patossistema temperado}

Modelos são representações simplificadas de um sistema. Quanto simplificar e como simplificar dependem, dentre outros fatores, do objetivo que se espera alcançar com o modelo. Na construção do modelo somente são considerados os elementos essenciais para que o objetivo seja alcançado, ignorando-se aqueles secundários. Os bons autores (Spedding, 1988) nos lembram que sem um objetivo claro, definido $a$ priori, não se pode decidir o que é e o que não é essencial.

Objetivos simples permitem o emprego de modelos simples. Pode-se, por ora, prescindir do grande poder de abstração dos modelos simbólicos, diagramáticos ou matemáticos, e ficar com os mais intuitivos modelos analógicos. Examine a Figura 1, originalmente proposta por Fegies (1985). O conceito de sítio de infecção é importante para entender o modelo proposto. A população do hospedeiro está representada por um grande, mas finito, número de sítios de infecção, todos com o mesmo tamanho. A dimensão física de um sítio de infecção coincide, para algumas doenças, com a área da lesão causada pelo patógeno. A caixa que contém os sítios sadios na Figura 1 representa, antes do início da epidemia, toda a população do hospedeiro. A epidemia tem início com a deposição de um esporo de fora do sistema sobre um sítio sadio. Com a infecção que advém desse primeiro contato patógeno-hospedeiro o sítio que era sadio torna-se doente ou, mais precisamente, latente. Os eventos que ocorrem durante a colonização, aparecimento de sintomas, etc., também são ignorados no modelo. A próxima etapa importante ocorre após completado o período latente (quatro dias no exemplo proposto). Note que durante esses quatro dias a epidemia não progride. O número de sítios doentes (latentes, no caso) mantém-se constante em um. No quinto dia, porém, o sítio doente deixa de ser latente e passa a ser infeccioso, permanecendo como tal, segundo o modelo, por mais quatro dias. Durante esse período, definido como período infeccioso, o sítio, diariamente, produz esporos. Grande parte deles é perdida durante as várias etapas compreendidas entre sua produção e novas infecções. A torneira situada logo abaixo dos sítios infecciosos representa essa perda. Alguns poucos, porém, seguem pela tubulação (aqui chamada de via horária de infecção) e vão causar novas infecções. Esse modelo analógico de epidemia temperada está de acordo com a epidemiologia clássica de Vanderplank (1963), com a síntese de Gäumann (1950) e, também, com a idéia que se faz de típicos patossistemas temperados, como maçã (Malus domestica Borkh.)/Venturia inaequalis (Cooke) Wint. e trigo (Triticum aestivum L.)/Puccinia graminis Pers..

O modelo analógico de Fegies (Figura 1), proposto como uma representação do fitopatossistema temperado, deixa explícito que a via horária de infecção é o único caminho para sítios sadios tornarem-se doentes. A produção de esporos durante o período infeccioso, juntamente com o parâmetro temporal correlato - período latente -, é o pilar onde se assenta

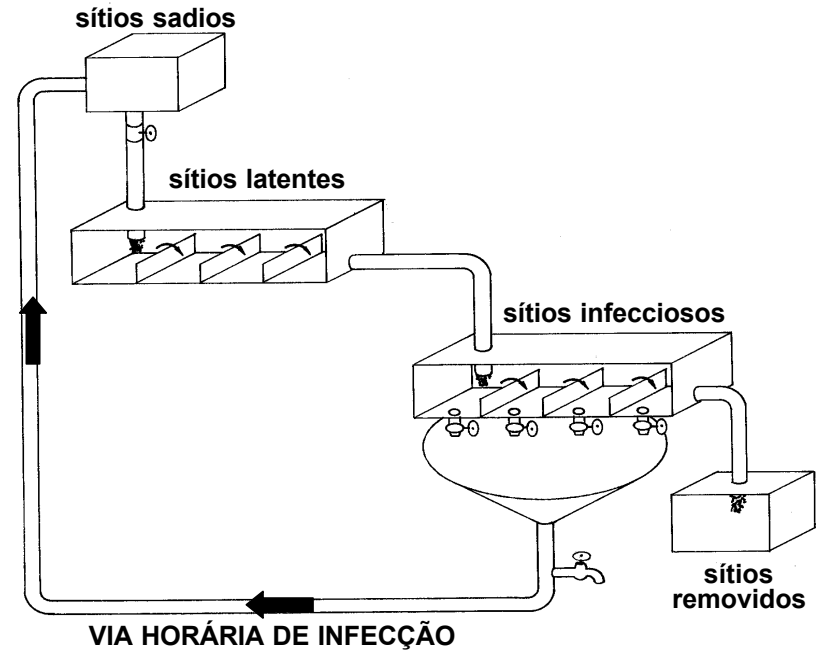

FIG. 1 - Modelo analógico de Fegies para o patossistema temperado. A população do hospedeiro, antes do início da epidemia, está representada por um número finito de sítios contidos na caixa de sítios sadios. A epidemia tem início com a infecção causada por um esporo externo ao sistema (não representado). Cada compartimento dentro de sítios latentes e infecciosos representa um dia. A via horária de infecção é a única possibilidade de sítios sadios tornarem-se doentes. Baseado em Fegies (1985).

a epidemiologia temperada para explicar o aumento da intensidade de doença em função do tempo. Os esporos produzidos, após serem liberados, transportados e depositados, germinarão, penetrarão e produzirão novas lesões, com mais esporos. Essa seqüência é o ciclo de infecção, que leva à cadeia de infecção, e que explica a ocorrência das epidemias. É também a via horária de infecção. Tudo na epidemiologia temperada, depreende-se da literatura, pode ser explicado pelo número maior ou menor de esporos produzidos (Vanderplank, 1963; Johnson \& Taylor, 1976; Zadoks \& Schein, 1979; Campbell \& Madden, 1990).

\section{O PATOSSISTEMA TROPICAL}

Depender totalmente da via horária de infecção para garantir a sobrevivência, porém, colocaria grande parte dos patógenos tropicais em perigo. Afinal, nem todos são tão eficientes quanto Puccinia graminis f. sp. tritici Eriks. \& Henn., agente causal da ferrugem do colmo do trigo, que no seu hábitat preferido, as regiões temperadas, encontra, durante a estação de cultivo, condições propícias para infetar seu hospedeiro, como temperaturas amenas e abundância de orvalho. Os trópicos não são tão condescendentes com seus patógenos foliares, quase sempre ávidos por água líquida sobre a folha para poderem germinar e penetrar. Nos trópicos, o orvalho é escasso (Rotem, 1978) e as condições gerais de clima impõem diversas limitações aos patógenos (Palti, 1981). 
Epidemiologia comparativa entre os patossistemas temperado e tropical: consequiências...

Modelos para o patossistema tropical

Uma hipótese de trabalho que explicite a principal diferença entre os patossistemas temperado e tropical parece apropriada neste momento (Bergamin Filho \& Amorim, 1996):

\section{Hipótese 1 - "Doenças que têm apenas a via horária de infecção geralmente não são importantes nos trópicos"}

Uma via alternativa de infecção: essa foi a solução encontrada pelos patógenos bem-sucedidos para não ficarem à mercê da inclemência do clima tropical (Figura 2). A via anti-horária de infecção representa o crescimento da lesão. Em outras palavras, sítios doentes podem gerar novos sítios doentes por meio da infecção dos sítios adjacentes àqueles previamente doentes, sem que seja necessário o concurso de esporos e da temerária, para os patógenos tropicais, via horária de infecção. Assim, o progresso da doença pode ser explicado tanto pelo aumento de novas lesões (via horária) quanto pelo crescimento das lesões existentes (via antihorária). O balanço nos trópicos, como se verá a seguir, tende para a segunda situação. A grande vantagem dessa estratégia, para o patógeno, é que o crescimento da lesão depende menos de condições climáticas do que a infecção por meio de esporos.

Trabalhos que reconhecem a importância do crescimento da lesão no desenvolvimento de uma epidemia são escassos tanto na literatura tropical quanto na temperada. Berger (1973), ao monitorar Exserohilum turcicum (Pass.) Leonard \& Suggs na Flórida, foi um dos primeiros a constatar que "poucas lesões novas apareceram após o florescimento

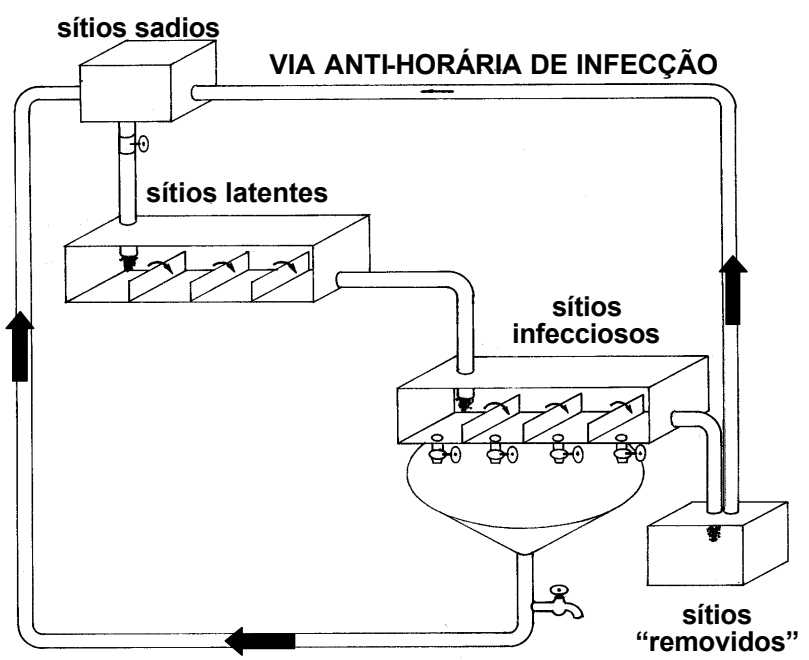

VIA HORÁRIA DE INFECCÇÃO

FIG. 2 - Modelo analógico para o patossistema tropical. Sítios sadios podem se tornar doentes pela via horária de infecção e pela via anti-horária de infecção (crescimento da lesão). Baseado em Bergamin Filho \& Amorim (1996).
(...) e a maior parte do aumento da doença deveu-se ao crescimento das lesões". Mais explícitos ainda foram Emge et al. (1975) que, apesar de trabalharem em região tipicamente temperada (Oregon, E.U.A), deixaram claro o importante papel desempenhado pelo crescimento da lesão no desenvolvimento de Puccinia striiformis West., em trigo, ao escrever: "o crescimento da lesão permite a intensificação da doença na ausência de condições favoráveis para a reinfecção e afeta profundamente a epidemiologia da doença". Um simulador desenvolvido para esse patossistema (Shrum, 1975) mostrou que uma redução de 50\% na velocidade de crescimento da lesão tem efeito maior no desenvolvimento da epidemia que uma redução da mesma magnitude na quantidade de esporos produzidos.

Reconhecimentos explícitos do papel importante do crescimento da lesão na epidemiologia tropical têm sido publicados com ainda maior parcimônia. Bastante ilustrativo, porém, é o trabalho de Chee (1976), a respeito da quantificação da resistência de clones de seringueira [Hevea brasilienses (Willd. ex Adr. de Juss.) Muell. \& Arg.] a Microcyclus ulei (Henn.) v. Arx. Contrariando a expectativa geral, a caracterização de clones não pôde ser feita por meio da variável 'esporulação do patógeno', variável essa considerada por Johnson \& Taylor (1976) como a melhor representação da soma de todos os componentes da resistência. Nas palavras do próprio K.H. Chee, "a esporulação por meio de conídios foi, em geral, mais prolifica nos clones suscetiveis que nos resistentes, mas a inconsistência desse caráter não permitiu a separação confiável dos clones em diferentes categorias de suscetibilidade". O mesmo autor prossegue dizendo que "o tamanho da lesão, por outro lado, foi mais consistente de um teste para outro" e conclui: "estas observações sobre esporulação em discos de folha (...) confirmam aquela de Langford (1945), a respeito da inconsistência da esporulação em relação à suscetibilidade”.

De uns anos para cá, a literatura produzida nos países temperados tem registrado, com um pouco mais de freqüência, menções à importância do crescimento da lesão no processo epidêmico. Berger \& Jones (1985) incluíram rotinas específicas, ainda que rudimentares, para quantificar essa via. Mundt (1989) reconhece que o modelo de simulação EPIMUL, desprovido de rotinas para o crescimento da lesão, é adequado somente para aquelas doenças cujas lesões crescem pouco e comenta: "para outras doenças, entretanto, a área da lesão é indeterminada e uma única lesão pode crescer e cobrir grande proporção da folha. Esse crescimento pode ser extremamente importante para determinar a taxa de desenvolvimento da epidemia”. Hau (1990) é ainda mais claro e direto quando escreve: "nos modelos analíticos usados até aqui, assume-se que a doença pode aumentar somente quando novas infecções forem produzidas. Embora essa premissa seja verdadeira para algumas doenças, como as ferrugens, ela não é válida quando o crescimento da lesão também contribuir para o progresso da doença. Nesses casos, a curva de progresso da doença pode aumentar mesmo sob condições desfavoráveis para a infecção". Mais recentemente, Lannou 
(1992), após enfatizar a importância do crescimento da lesão, aborda um aspecto pouco discutido na literatura: a ocupação de novos sítios por meio do crescimento da lesão, com a conseqüente produção de novos esporos pelo patógeno, "ocorre num tempo bastante curto relativo ao período latente das infecções originárias da dispersão de esporos”. Uma revisão completa sobre o papel do crescimento da lesão na epidemiologia das doenças de plantas foi publicada recentemente (Berger et al., 1997).

As opiniões externadas no parágrafo anterior, de grande valia, sem dúvida, têm contra si o fato de terem sido, todas, baseadas em simuladores de doenças de plantas. Trabalhos recentes sobre a importância do crescimento da lesão baseados em dados experimentais são ainda mais raros. Exceção que confirma a regra é a pesquisa de Johnson \& Teng (1990) com o sistema batata (Solanum tuberosum L.) Alternaria solani (Ell. \& Mart.) Jones \& Grout. De interesse particular no contexto deste item é a constatação, por aqueles autores, que o "crescimento da lesão foi a variável mais sensivel, indicando que, embora novas infecções possam ocorrer, a maior parte do aumento da doença (...) foi causada pelas lesões preexistentes". E mais: "a magnitude dos danos devidos a relativamente pequenas mudanças no crescimento da lesão indica ser esta variável particularmente útil como um critério de seleção no melhoramento para resistência contra essa doença”.

Parece surpreendente que os despretensiosos modelos analógicos representados nas Figuras 1 e 2 tenham sido capazes de fornecer uma visão clara, quase quantitativa, de como funcionam as epidemias temperadas e tropicais. Numa primeira etapa identificou-se a via horária, com todas as implícitas complicações do ciclo de infecção, como o único caminho possível para que sítios sadios fossem ocupados pelo patógeno. Enquanto isso ainda se mantém verdadeiro para diversos patógenos temperados, ficou evidente que aqueles não tão eficientes nessa via deveriam ter outras opções para sobreviver em condições de orvalho escasso e temperatura alta demais. Da constatação desse fato até a formulação de outra via, a via anti-horária de infecção, menos dependente do clima para se concretizar, o caminho não foi difícil (Bergamin Filho \& Amorim, 1996). Mas nem tudo está explicado. Duas doenças tropicais, o mal das folhas da seringueira causado por M. ulei e o mal de Sigatoka da bananeira (Musa spp.) causado por Mycosphaerella musicola Leach, merecem um exame mais detalhado. Ambas são, provavelmente, as duas mais graves doenças conhecidas. Graves não só pela magnitude dos danos causados à produção como, principalmente, pela freqüência com que esses danos ocorrem: na ausência de medidas de controle, esses dois patógenos, todos os anos, provocam severas epidemias, como se estivessem acima das leis que governam a infecção, como se o crescimento da lesão fosse uma dádiva sempre concedida, como se o clima, para eles, enfim, fosse sempre um cúmplice. A conveniência de formular, agora, uma segunda hipótese didática de trabalho parece inquestionável (Bergamin Filho \& Amorim, 1996):
Hipótese 2 - "Doenças sempre importantes nos trópicos têm, além da via anti-horária de infecção, dois tipos de via horária de infecção"

O exame do ciclo de vida de $M$. ulei e de M. musicola fornece uma pista para as razões dessa anormal inclinação por causar epidemias. Ambas as vias de infecção já discutidas, a horária e a anti-horária, certamente estão presentes. A mais, porém, os dois patógenos, ao contrário de quase todos os outros, produzem dois tipos de esporo durante a fase epidêmica da doença: sexual e assexual. Nas outras doenças, o primeiro tipo, quando ocorre, é sempre responsável unicamente pela sobrevivência do patógeno entre estações de cultivo. Após cumprida essa missão, ele não mais é produzido e não contribui, assim, para o desenvolvimento da epidemia, tarefa desempenhada pelo segundo tipo de esporo. Venturia inaequalis e $P$. graminis f. sp. tritici, ambos patógenos tipicamente temperados, são bons exemplos desse padrão de comportamento.

A ocorrência de dois tipos de esporos durante a fase epidêmica da doença traz modificações importantes no modelo analógico de epidemia tropical e permite a definição de dois tipos de via horária de infecção: a via horária assexual e a via horária sexual (Figura 3 ). Ambas têm características distintas, usualmente complementares, podendo também, sob condições ideais, tornarem-se aditivas (Bergamin Filho \& Amorim, 1996). É essa flexibilidade de comportamento que permite a $M$. ulei e a $M$. musicola ignorarem as muitas restrições de ordem climática que o processo horário de infecção usualmente apresenta.

\section{A sobrevivência do inóculo}

Além das diferenças mencionadas até aqui, a sobrevivência do inóculo entre estações de cultivo também é um ponto bastante citado para diferenciar os patossistemas

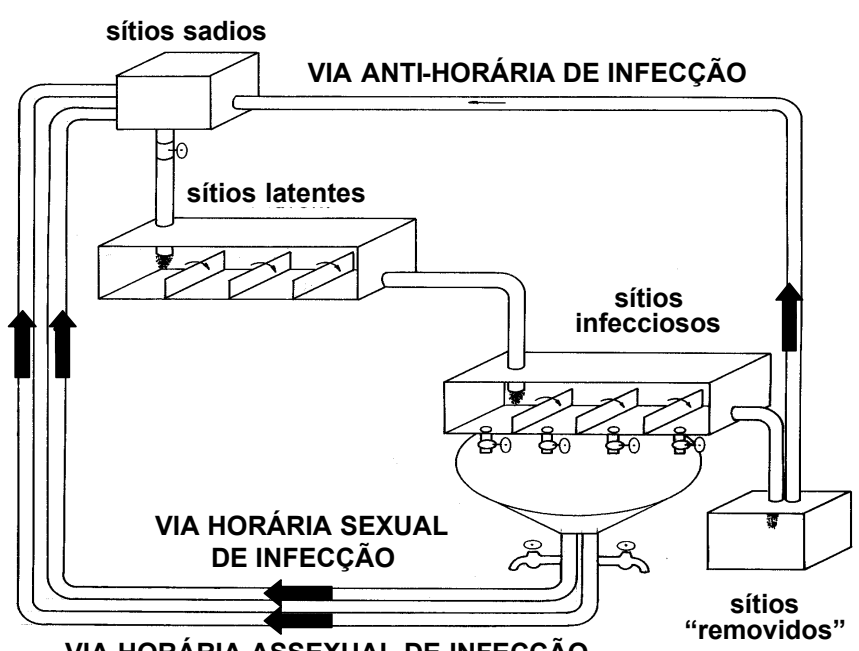

VIA HORÁRIA ASSEXUAL DE INFECÇÃO

FIG. 3 - Modelo analógico para o patossistema tropical com três vias de infecção: anti-horária, horária assexual e horária sexual. Baseado em Bergamin Filho \& Amorim (1996). 
Epidemiologia comparativa entre os patossistemas temperado e tropical: consequiências...

temperado e tropical. Muitos autores referem-se a esse princípio. Assim, Gäumann (1950) deixa claro que "cadeias de infecção intermitentes são muito mais comuns em nossa zona de vegetação (zona temperada), onde o inverno (...) interrompe temporariamente a transmissão em série do patógeno de um hospedeiro para outro”; Sequeira (1962) enfatiza que os patógenos tropicais "crescem continuamente devido à falta de períodos prolongados de baixa temperatura"; Wellman (1962) escreve que "organismos parasitas nos trópicos não têm (...) a neve para interferir em seu crescimento”; Fröhlich \& Rodewald (1969) explicam que, nos trópicos, "raramente há qualquer interrupção no desenvolvimento e na seqüência de gerações de patógenos e insetos"; Waller (1976), entre outras considerações, afirma que "a falta de uma estação fria bem definida (...) é um dos fatores mais importantes" que governam o crescimento dos patógenos tropicais; Meyer (1978) enfatiza que "temperaturas sempre superiores à de congelamento influenciam profundamente os níveis populacionais do patógeno"; Rotem \& Palti (1980), além da incisão fria, também reconhecem a incisão seca, quando escrevem que "em locais com inverno frio ou verão seco e quente (...), o inóculo presente no início da estação vegetativa é relativamente baixo. Ele é sempre mais baixo que o inóculo do mesmo patógeno presente em regiões de inverno ameno ou verão moderadamente quente e úmido, condições que permitem o cultivo do hospedeiro durante todo o ano"; Thurston (1998) também baseia seu recente livro "Tropical Plant Pathology" nessa característica dos trópicos e subtrópicos e mesmo Vanderplank (1984), em seu último livro, afirma que "doenças em regiões tropicais têm algumas características especiais, como uma maior continuidade de inóculo".

A literatura sobre sobrevivência do patógeno e continuidade do inóculo é abundante quando se considera o relativamente longo intervalo de tempo entre estações de cultivo. No entanto, existe um outro enfoque sobre sobrevivência e continuidade do inóculo que raramente é mencionado na literatura, qual seja, aquele que considera o curto intervalo de tempo entre a esporulação do patógeno e a infecção do hospedeiro (Bergamin Filho \& Amorim, 1996). Esse período, que se repete inúmeras vezes durante o ciclo da maioria dos patógenos foliares, tem grande importância epidemiológica, e as evidências colhidas na literatura indicam, geralmente, que as regiões temperadas, quando comparadas com as tropicais, propiciam aos patógenos consideráveis vantagens, seja considerando a temperatura (esporos de fungos sobrevivem melhor a baixas temperaturas), seja considerando a umidade (esporos de fungos sobrevivem mais tempo sob baixa umidade relativa), seja considerando a radiação solar (bactérias e fungos são adversamente afetados por alta radiação solar). Além disso, a duração do orvalho, condição indispensável para a infecção, é menor em regiões mais quentes e ensolaradas (Rotem, 1978).

Assim, a sobrevivência do patógeno é crítica entre estações de cultivo para as regiões temperadas e, ao contrário, entre a esporulação e a infecção para a região tropical
(Bergamin Filho \& Amorim, 1996).

\section{A taxa aparente de infecção (r)}

A taxa aparente de infecção $(r)$, conceituada originalmente por Vanderplank (1963), é apenas um velocímetro da epidemia (Vanderplank, 1975). Por ser extremamente sensível aos efeitos do clima no desenvolvimento das doenças em populações (Kranz, 1978), constitui-se, porém, numa variável extremamente útil para a comparação de epidemias que se desenvolvem em regiões temperadas e tropicais. As evidências disponíveis são esparsas e quase sempre indiretas, pois inexistem pesquisas feitas especificamente para esclarecer essa questão.

Palti (1981) é um dos poucos autores a, explicitamente, reconhecer que as regiões tropicais impõem diversas limitações climáticas aos patógenos. Buddenhagen (1977) também acredita que os trópicos não são vulneráveis à ocorrência de epidemias, mas centraliza sua discussão na maior heterozigosidade das culturas tropicais para justificar sua hipótese. Provavelmente, ambos os autores têm razão, mas os fatores climáticos estão melhor estudados e serão examinados com maior detalhe neste item.

Bergamin Filho \& Amorim (1996) são de opinião que os agroclimas tropicais provocam um mais lento desenvolvimento da epidemia, expresso por uma taxa aparente de infecção (sensu Vanderplank, 1963) mais baixa. As evidências vêm de várias direções: o orvalho, de menor freqüência e duração nos trópicos (Rotem, 1978), é importante fator também para a esporulação de um grande número de fungos, havendo inclusive casos de ausência completa de esporulação sem sua ocorrência; a combinação de temperaturas elevadas e alta intensidade luminosa, característica dos trópicos, inibe o estágio final da esporogênese de muitos patógenos; altas temperaturas também diminuem a capacidade de causar epidemias tanto de parasitas obrigados quanto de parasitas facultativos, estes em virtude da diminuição do período infeccioso e aqueles pela necrose precoce dos tecidos do hospedeiro; radiação solar intensa também tende a inibir o desenvolvimento de epidemias em alguns sistemas patógenohospedeiro (Bergamin Filho \& Amorim, 1996).

Nem todos os patossistemas tropicais, no entanto, têm taxas aparentes de infecção mais baixas que aquelas exibidas pelos patossistemas temperados: aqueles que, além da via antihorária de infecção, possuem duas vias horárias (sexual e assexual) são exemplos típicos (Item 2.1, Figura 3).

\section{RESISTÊNCIA DE FUNGOS A FUNGICIDAS}

A resistência de fungos a fungicidas tem sido estudada intensamente na região temperada, especialmente nos E.U.A. e em alguns países europeus (Inglaterra, Holanda, França e Alemanha). Os conceitos e princípios aceitos atualmente encontram-se bem descritos na literatura (Delp, 1988; Brent, 1995; Brent \& Hollomon, 1998; Kendall \& Hollomon, 1998) e têm sido aplicados progressivamente naqueles países. No Brasil, recentemente, um apanhado geral desses conceitos e 
princípios foi publicado (Ghini \& Kimati, 2000).

Didaticamente, pode-se dividir o assunto em duas partes: (i) a origem da resistência e sua posterior (ii) seleção ("build up"). Geralmente, linhagens fúngicas resistentes originam-se por meio de mutação. Mutantes de todos os tipos estão aparecendo e desaparecendo continua e espontaneamente na natureza. A freqüência de aparecimento de mutantes resistentes é função, principalmente, do grupo químico a que pertence o fungicida em questão: há grupos (benzimidazóis, dicarboximidas, fenilamidas) que agem em uma ou poucas rotas metabólicas do fungo (nesse caso a resistência é chamada de qualitativa), ao contrário de outros (DMI, morfolinas), que agem em múltiplas rotas metabólicas (resistência quantitativa). Para estes, o aparecimento de mutantes resistentes é pouco frequiente, ao contrário daqueles. Outros dois fatores contribuem para a ocorrência de mutantes resistentes: tamanho da população do fungo no momento da aplicação (quanto maior a população, maior a chance de ocorrência de mutantes resistentes) e presença de reprodução sexual (a reprodução sexual pode aumentar a ocorrência de indivíduos resistentes).

Após a origem, a seleção de mutantes resistentes na natureza é função principal do próprio patossistema (principalmente o potencial reprodutivo do patógeno e sua adaptabilidade ao meio ou "fitness") e da pressão de seleção exercida sobre a população sensível.

Patógenos com alto potencial reprodutivo (alta esporulação, curto período latente, longo período de infecção, alta eficiência de infecção, etc.) são sempre mais rapidamente selecionados. Da mesma maneira, mutantes resistentes que não tenham comprometida nenhuma função de importância epidemiológica (reprodução, sobrevivência, capacidade de disseminação, etc.) também têm maiores chances de prevalecerem na população.

A pressão de seleção exercida sobre a população do fungo é, provavelmente, o fator mais importante envolvido na seleção da resistência. Quanto maior a pressão de seleção contra a população original (sensível), mais rápida será a substituição desta por indivíduos resistentes. Altas pressões de seleção, assim, anulam a competição por sítios de infecção; como conseqüência, anulam qualquer eventual desvantagem seletiva que possam ter os indivíduos resistentes. Dentre os principais fatores que levam a uma maior pressão de seleção estão: (i) maior eficiência do fungicida, (ii) maior frequiência de aplicação do fungicida, (iii) melhor cobertura e maior persistência do fungicida, (iv) maior diferença em sensibilidade entre indivíduos resistentes e sensíveis e (v) menor ingresso e/ou manutenção de indivíduos sensíveis na área considerada.

Com base nesses fatores, a literatura publicada nos países temperados (por exemplo, Heaney et al., 1994; Brent, 1995; Brent \& Hollomon, 1998; Kendall \& Hollomon, 1998) recomenda várias medidas para diminuir o risco de seleção de indivíduos resistentes numa determinada área, como: (i) evitar tratamentos repetitivos com o mesmo fungicida; (ii) misturar diferentes fungicidas compatíveis e apropriados; (iii) alternar produtos apropriados; (iv) limitar o número de aplicações; (v) espaçar as aplicações no tempo; (vi) evitar uso erradicante ou curativo do fungicida; (vii) usar o fungicida como protetor; (viii) usar dosagem recomendada; (ix) integrar o tratamento químico com táticas de controle não-químicas.

\section{O PATOSSISTEMA TROPICAL E A RESISTÊNCIA A FUNGICIDAS}

As características dos patossistemas tropical e temperado (item 1) serão comparadas entre si com o objetivo de inferir conceitos e princípios que orientem a tomada de decisão sobre como evitar ou retardar a origem e a seleção de populações resistentes a fungicidas nos trópicos. Para fins didáticos, a comparação envolverá o patossistema temperado (Figura 1) e dois tipos de patossistema tropical, referidos como 'tropical I' (uma via horária de infecção, Figura 2) e 'tropical II' (duas vias horárias de infecção, Figura 3). Os dois tipos de sobrevivência definidos no item 2.2 serão chamados de 'sobrevivência I' (entre estações de cultivo) e 'sobrevivência II' (entre ciclos do patógeno).

Dos diversos fatores que podem influenciar a origem e a posterior seleção de mutantes resistentes a fungicidas, alguns não apresentam potencial para discriminar os três patossistemas considerados em virtude de, geralmente, serem comuns a todos eles: (i) grupo químico; (ii) frequiência de mutação; (iii) eficiência do fungicida; (iv) freqüência de aplicação; (v) cobertura do fungicida na planta; (vi) diferença de sensibilidade entre populações sensíveis e resistentes.

Outros fatores, no entanto, por terem ação diferencial em, pelo menos, dois dos três patossistemas considerados, serão analisados neste item (fatores diferenciais). São eles: (i) sobrevivência I; (ii) sobrevivência II; (iii) taxa aparente de infecção; (iv) via anti-horária de infecção; (v) ingresso e/ ou manutenção de sensíveis na área considerada; (vi) via horária sexual ocorrendo durante toda a epidemia; (vii) persistência do fungicida na planta; (viii) adaptabilidade dos mutantes resistentes. $\mathrm{O}$ resultado da análise, considerando os riscos de origem e de seleção de mutantes resistentes para os patossistemas tropical I e tropical II (sempre em relação ao patossistema temperado) está apresentado esquematicamente na Figura 4 (seta para cima indica risco maior em relação ao patossistema temperado; seta para baixo, risco menor; traço, risco inalterado), que serve de base para a discussão que vem a seguir. Deve-se ter em mente, no entanto, a natureza inédita e especulativa dessa discussão, uma vez que dados reais de campo praticamente inexistem para a região tropical.

Com relação ao fator sobrevivência I, os patossistemas tropicais I e II são mais sujeitos a problemas com resistência a fungicidas, tanto em relação à origem quanto à seleção, em virtude da maior continuidade de inóculo entre estações de cultivo que caracteriza esses patossistemas (item 2.2).

A situação modifica-se quando o fator diferencial sobrevivência II (item 2.2) é considerado: o risco é menor para o patossistema tropical I, em virtude das condições climáticas tropicais serem menos favoráveis (em relação ao 
Epidemiologia comparativa entre os patossistemas temperado e tropical: consequiências...

patossistema temperado) para a infecção pela via horária (item 2.1). Pelo mesmo motivo, o fator taxa aparente de infecção também sugere riscos menores para o patossistema tropical I (item 2.3). A presença de duas vias horárias de infecção (sexual e assexual) durante toda a epidemia no patossistema tropical II (item 2.1, hipótese 2) faz com que o risco de resistência a fungicidas seja semelhante àquele do patossistema temperado, tanto para o fator sobrevivência II (item 2.2) quanto para o fator taxa aparente de infecção (item 2.3).

A presença da via anti-horária de infecção (item 2.1, hipótese 1, Figuras 2 e 3), representada pelo crescimento da lesão em ambos os patossistemas tropicais, faz com que a manutenção de indivíduos sensíveis na área considerada seja maior que no patossistema temperado (lesões maiores dificultam a erradicação química do patógeno). Essa característica diminui a pressão de seleção exercida contra a população sensível (item 3), o que leva a uma diminuição do risco de seleção de indivíduos resistentes tanto no patossistema tropical I quanto no II.

A via horária sexual atuando durante toda a epidemia, característica do patossistema tropical II (item 2.1, hipótese 2, Figura 3), tem efeito diferente quando se considera a origem e a seleção de indivíduos resistentes. Assim, reprodução sexual durante longo período de tempo pode favorecer a origem de recombinantes resistentes e bem adaptados (aloinfecção sensu Robinson, 1976), o que aumenta o risco de origem da resistência. Por outro lado, depois que indivíduos resistentes já se originaram (autoinfecção sensu Robinson, 1976), a reprodução sexual produzirá indivíduos segregantes sensíveis, o que reintroduz na população indivíduos sensíveis, diminuindo, assim, a pressão de seleção e, consequentemente, também diminuindo o risco de seleção da resistência (item 3 ).

A persistência do fungicida no campo (fator de aumento da pressão de seleção, item 3) é, em geral, menor no patossistema tropical, devido às mais frequientes chuvas de alta intensidade nessas regiões. Menor persistência leva a menor pressão de seleção (item 3) e a menor risco de seleção de indivíduos resistentes. Por último, indivíduos com adaptabilidade superior terão mais chance de ocorrer quanto mais freqüente for a reprodução sexual. Esse fator leva a um maior risco de seleção de resistência no patossistema tropical II (item 2.1, hipótese 2).

Um balanço geral do efeito de todos os fatores diferenciais considerados (supondo igual importância para todos eles, o que certamente não é verdadeiro; lembra-se novamente o caráter especulativo deste artigo) indica que o risco de seleção de indivíduos resistentes a fungicidas é menor no patossistema tropical, se comparado ao patossistema temperado (ver 'balanço', Figura 4). Quando o risco de origem de indivíduos resistentes é considerado, não há diferenças entre o patossistema temperado e o patossistema tropical I (balanço $=0$ ); o patossistema tropical II, no entanto, tem um risco de origem de indivíduos resistentes ligeiramente maior $($ balanço $=2)($ Figuras 4 e 5$)$.

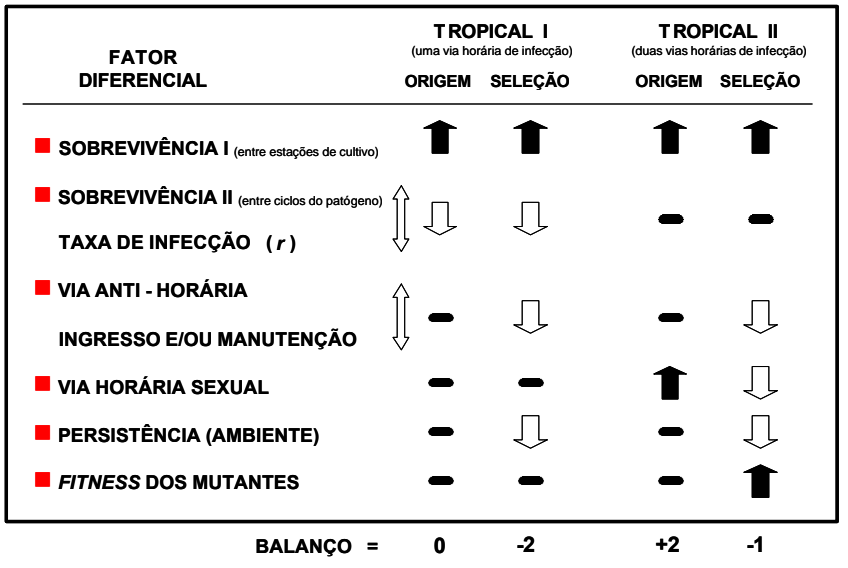

FIG. 4 - Fatores diferenciais de análise de risco para origem e seleção da resistência a fungicidas para os patossistemas tropical I e tropical II, em relação ao patossistema temperado. Setas para cima indicam risco maior; para baixo, risco menor; traço, risco inalterado (em relação ao patossistema temperado).

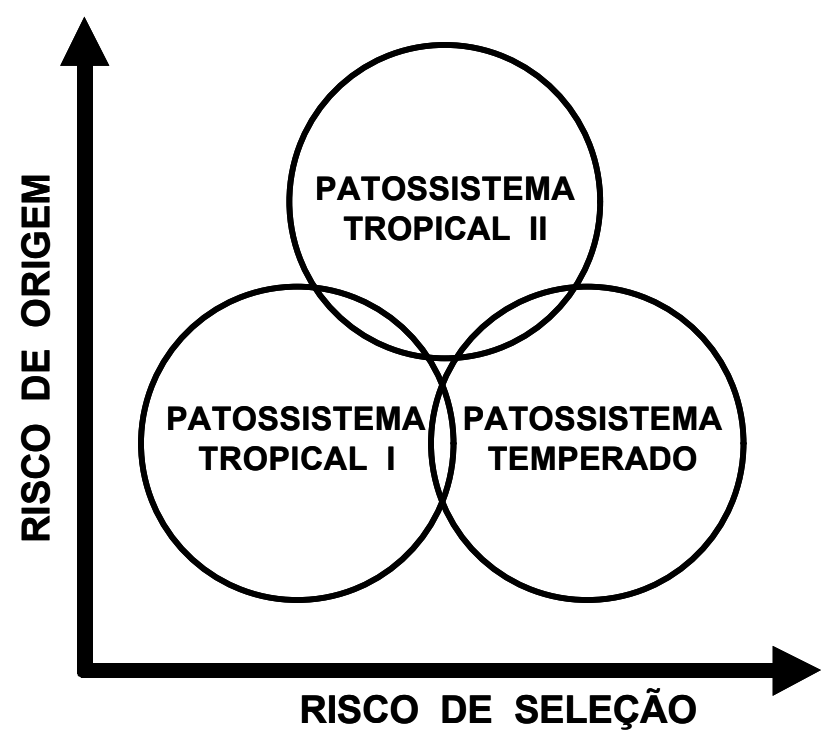

FIG. 5 - Riscos relativos de origem e seleção de resistência para os patossistemas temperado, tropical I e tropical II. Baseados nos fatores diferenciais da Figura 4.

Assim, sugere-se que o patossistema tropical, de modo geral, não apresenta, em relação ao temperado, maior risco de resistência a fungicidas. As estratégias desenvolvidas para os países temperados (item 3), caso funcionem no contexto temperado, também funcionarão no contexto tropical.

\section{AGRADECIMENTOS}

Ao Professor Sami Michereff e ao grupo de estudantes 
de pós-graduação da UFRPE (julho de 2000), que ajudaram a desenvolver os conceitos apresentados neste artigo. Ao FRAC ("Fungicide Resistance Action Committee"), na pessoa de seu presidente no Brasil, Eric Guicherit, por ter sugerido o tema e patrocinado a participação do primeiro autor no congresso da Sociedade Brasileira Fitopatologia, agosto de 2000, em Belém. Ao doutor Waldir Cintra de Jesus Jr., pelas sugestões.

\section{REFERÊNCIAS BIBLIOGRÁFICAS}

BERGAMIN FILHO, A. \& AMORIM, L. Doenças de Plantas Tropicais: Epidemiologia e Controle Econômico. Ceres, São Paulo. 1996.

BERGER, R.D. Helminthosporium turcicum lesion numbers related to numbers of trapped spores and fungicide sprays. Phytopathology 63:930-933. 1973.

BERGER, R.D., BERGAMIN FILHO, A. \& AMORIM, L. Lesion expansion as an epidemic component. Phytopathology 87: 1005-1013. 1997.

BERGER, R.D. \& JONES, J.W. A general model for disease progress with functions for variable latency and lesion expansion on growing host plants. Phytopathology 75:792-797. 1985.

BRENT, K.J. Fungicide Resistance in Crop Pathogens: How it Can Be Managed? FRAC Monograph 1, Brussels. 1995.

BRENT, K.J. \& HOLLOMON, D.W. Fungicide Resistance: The Assessment of Risk. FRAC Monograph 2, Brussels. 1998.

BUDDENHAGEN, I.W. Resistance and vulnerability of tropical crops in relation to their evolution and breeding. In The genetic basis of epidemics in agriculture. Annals of the New York Academic of Sciences 287:309-326. 1977.

CAMPBELL, C.L. \& MADDEN, L.V. Introduction to Plant Disease Epidemiology. Wiley, New York. 1990.

CHEE, K.H. Assessing susceptibility of Hevea clones to Microcyclus ulei. Annals of Applied Biology 84:135145. 1976.

DELP, C.J. Fungicide Resistance in North America. APS Press, St. Paul. 1988.

EMGE, R.G., KINGSOLVER, C.H. \& JOHNSON, D.R. Growth of sporulating zone of Puccinia striiformis and its relationship to stripe rust epiphytology. Phytopathology 65:679-681. 1975.

FEGIES, N.C. Desenvolvimento de modelos para simulação da progressão de doenças de plantas. Dissertação de Mestrado, ESALQ, Piracicaba. 1985.

FRÖHLICH, G. \& RODEWALD, W. Pests and Diseases of Tropical Crops and Their Control. Pergamon Press, Oxford. 1969.

GÄUMANN, E. Principles of Plant Infection. Crosby Lockwood \& Sons, London. 1950.

GHINI, R. \& KIMATI, H. Resistência de Fungos a Fungicidas. EMBRAPA-FRAC, Jaguariúna-SP. 2000.
HAU, B. Analytic models of plant disease in a changing environment. Annual Review Phytopathology 28:221245. 1990

HEANEY, S; SLAWSON, D.; HOLLOMON, D.W.; SMITH, M.; RUSSEL, P.E. \& PARRY, D.W. Fungicide Resistance. British Cropo Protection Council Monograph 60, Farnham. 1994.

JOHNSON, K.B. \& TENG, P.S. Coupling a disease progress model for early blight to a model of potato growth. Phytopathology 80:416-425. 1990.

JOHNSON, R. \& TAYLOR, A.J. Spore yield of pathogens in investigations of the race specificity of host resistance. Annual Review Phytopathology 14:97-119. 1976.

KENDALL, S.J. \& HOLLOMON, D.W. Fungicide resistance. In Fungicide Activity. Chemical and Biological Approaches to Plant Protection. D.H. HUTSON \& MIYAMOTO, J., Ed. Wiley, Chichester. 1998.

KRANZ, J. Comparative epidemiology. In Plant Disease an Advanced Treatise. How Disease Develops in Populations (Vol. II). HORSFALL, J.G. \& COWLING, E.B., Ed. Academic Press, New York. 1978.

LANGFORD, M.H. South American leaf blight of Hevea rubber trees. Tech. Bull. U.S. Dep. Agric. 882. 1945.

LANNOU, C. Étude par la simulation de l'efficacité d'un mélange varietal pour limiter le développement des épidémies. Effect de la croissance des lésions du parasite, rôle de la résistance induite. Thèse de Doctorat, Université Paris XI, Orsay. 1992.

MEYER, J.A. Plant pathology and tropical countries. In Diseases of Tropical Food Crops. Maraite, H. \& Meyer, J.A., ed. Proceedings of an international symposium, Louvain-la-Neuve. 2-5. 1978.

MORRAL, R.A.A. \& VERMA, P.V. Disease progress curves, linear transformations, and common root rot of cereals. Canadian Journal Plant Pathology 3:182-183. 1981.

MUNDT, C.C. Modeling disease increase in host mixtures. In Plant Disease Epidemiology. Genetics, Resistance and Management (Vol. II). LEONARD, K.J. \& FRY, W.E., Ed. McGraw-Hill, New York. 150-181. 1989.

PALTI, J. Cultural Practices and Infectious Crop Diseases. Springer, Berlin. 1981.

ROBINSON, R.A. Plant Pathosystems. Springer, Berlin. 1976.

ROTEM, J. Climatic and weather influences on epidemics. In Plant Disease an Advanced Treatise. How Disease Develops in Populations (Vol. II). HORSFALL, J.G. \& COWLING, E.B., Ed. Academic Press, New York. 1978.

ROTEM, J. \& PALTI, J. Epidemiological factors as related to plant disease control by cultural practices. In: PALTI, J. \& KRANZ, J. (Eds.) Comparative Epidemiology. A Tool for Better Disease Management. Pudoc, Wageningen. 1980.

SEQUEIRA, L. Special contributions from the tropics to phytopathological mycology. Phytopathology 52:936942. 1962.

SHRUM, R.D. Simulation of wheat stripe rust (Puccinia 
Epidemiologia comparativa entre os patossistemas temperado e tropical: consequiências...

striiformis West) using EPIDEMIC, a flexible plant disease simulator. Penn. State Univer. Agric. Exp. Stn. Prog. Rep. 347. 1975.

SPEDDING, C.R.W. An Introduction to Agricultural Systems. Elsevier, London. 1988.

THURSTON, H.D. Tropical Plant Diseases. APS Press, St Paul. 1998.

VANDERPLANK, J.E. Plant Diseases: Epidemics and Control. Academic Press, New York. 1963.

VANDERPLANK, J.E. Principles of Plant Infection. Academic Press, New York. 1975.

VANDERPLANK, J.E. Disease Resistance in Plants. 2nd ed, Academic Press, Orlando. 1984.

WALLER, J.M. The influence of climate on the incidence and severity of some diseases of tropical crops. Review of Plant Pathology 55:185-194. 1976.

WELLMAN, F.L. A few introductory features of tropical plant pathology. Phytopathology 52:928-930. 1962.

ZADOKS, J.C. Methodology of epidemiological research. Annual Review Phytopathology 10:253-276. 1972.

ZADOKS, J.C. \& SCHEIN, R.D. Epidemiology and Plant Disease Management. Oxford University Press, New York. 1979.

ZADOKS, J.C. \& SCHEIN, R.D. Epidemiology and plantdisease management, the known and the needed. In: PALTI, J. \& KRANZ, J. (Eds.) Comparative Epidemiology. A Tool for Better Disease Management. Pudoc, Wageningen. 1980. 